\title{
Cadaveric skull and tissue cutting manipulator: autopsy equipment that provides safety against airborne infection and COVID-19
}

\author{
Arnon Jumlongkul ${ }^{1}$ (D) \\ Received: 12 May 2020 / Accepted: 13 October 2020 / Published online: 17 October 2020 \\ (C) Sociedade Brasileira de Engenharia Biomedica 2020
}

\begin{abstract}
Purpose Many autopsies, including COVID-19 cases, will be carried out where the cause of death, including COVID-19 cases, is unknown and the mortuary staffs will possibly be exposed to infectious bone dust and secretions. To help our funeral colleagues minimize their risk of infection, this manipulator was created to help prevent such serious events, as well as other conditions related to airborne diseases. This article provides some technical details necessary for creating an autopsy saw, including the machinery design, control system design, specification of devices, and other abilities of this machine.

Methods The manipulator consists of a control system, linear actuator motors, a gearbox with DC gear motor, DC gear servo coreless motor, and the out-runner brushless DC electric motor.

Results The results showed that the manipulator can be assembled to fit to, and be removed from, an autopsy bed without drilling into the bed surfaces. There is adjustment of the cutting range, both vertically and horizontally, via a remote control. The saw frame can be rotated through $360^{\circ}$ for skull and tissue cutting. The saw blade depth can be adjusted from 0 to $3 \mathrm{~cm}$. The rotational speed of the saw blade can be regulated from 0 to 10,080 RPM. The cutting procedure can be controlled remotely, up to $20 \mathrm{~m}$ away from the manipulator.

Conclusion In future projects, the instrument design should allow control incorporating "Internet of things" technology, be constructed under a multipurpose autopsy machine concept, and also autonomously conduct a full autopsy procedure.
\end{abstract}

Keywords Autopsy manipulator · Autopsy robot $\cdot$ COVID-19 $\cdot$ Safety mortuary $\cdot$ Skull cutting

\section{Introduction}

In this current situation, the number of deaths from the coronavirus disease 2019 or COVID-19 is likely increase in Europe, the USA, and other areas around the world. According to the infection and prevention control for a COVID-19 dead body, proposed by the World Health Organization, performed autopsies should be done either in an adequately negative pressure room with at least 12 air changes per hour or a natural ventilated room with at least $160 \mathrm{~L} / \mathrm{s} /$ patient air flow, respectively. Appropriate personal protective equipment (PPE) should be available for mortuary staff and also safety procedures must be followed as in all

Arnon Jumlongkul

arnon.jum@mfu.ac.th

1 School of Medicine, Mae Fah Luang University, Chiang Rai 57100, Thailand autopsies of a deceased person who died from any acute respiratory infection (World Health Organization 2020).

Sometimes in cases of death, who were diagnosed as a patient under investigation (PUI) and also the COVID-19 infection, it is necessary to open the internal cranial, thoracic, as well as the abdominal organs to answer questions relating to the cause of death. In Thailand, the criminal procedure code, Section 148, declares that any person who has died from an unnatural death or has died while being kept in officially sanctioned custody, an inquest shall be held. Unnatural deaths also include suicide death by the act of another person, death caused by an animal, death by accident, and death from a cause not yet known. In Section 151, whenever there is the necessity to ascertain the cause of death, the dissection of the corpse shall be done (International Labour Organization 2008). Therefore, inevitably mortuary staff will be conducting ongoing autopsy procedures.

As the COVID-19 situation in Brazil, which has been a high mortality rate, a new autopsy technique in suspected coronavirus deaths, also called the ultrasound-guided 
minimally invasive autopsy (MIA-US) technique, was applied to extract tissue samples from target organs. This procedure is more safe than and also has been equivalent standard to a conventional autopsy since the epidemic of yellow fever in 2018 (Nunes Duarte-Neto et al. 2020). Other minimally invasive autopsy techniques with postmortem imaging, which challenge the conventional autopsy, also include CT scans, MRI, and CT-guided biopsy. Some studies have confirmed that a combination of minimally invasive autopsy techniques shows similar results of detection of the cause of death, as well as higher diagnostic yields when compared with conventional autopsy methods (Blokker et al. 2018). Although these new techniques are safe and effective, particularly for COVID-19 cases, the related costs mean that these imaging technologies are not available to low- and middle-income countries.

Nowadays, almost all autopsies are carried out manually, whereas robotic technologies are being applied to many medical procedures, for instance, laboratory techniques, robotic-assisted surgery, telemedicine, medical imaging, etc. For skull and tissue cutting, the forensic pathologists always uses a knife, blade, hammer, scissor, chisel, handsaw, and other instruments, all of which require that the co-workers have to stay adjacent to the corpse. Clearly this situation may increase the risk of infection. A piece of electrical equipment, which is used in an autopsy room, is an oscillating saw, but this can produce heavy levels of bone dust and noise. A new device is a robotic autopsy saw, which was developed by our team. However, it has some limitations in that it is bulky, it can cut only either a skull or a spherically shaped object and is operated by a cable remote control (Jumlongkul and Chutivongse 2019).

As mentioned above, the objectives of this article are to describe steps in the design and fabrication of a cutting manipulator which can cut skull, bones, as well as soft tissue; secondly, to provide further information relating to innovative ideas for the creation of a medical device that can protect against airborne infection and against the ongoing COVID19 crisis; and finally, to create an improved safety environment for our mortuary staff, minimizing traumatic injuries and infectious conditions. The challenge was to provide a machine that may be used as an alternative, solving the restrictions of previous cutting devices.

\section{Methods}

The methodology of development of this autopsy manipulator is expressed as follows.

\section{Identifying problems}

Firstly, our autopsy room is located on the 1st floor of a building adjoining the main building of the Mae Fah Luang University
Medical Center Hospital, Chiang Rai, Thailand. There is only a single hydraulic autopsy bed and two funeral supplied tables for autopsy operations. Consequently, a compact machine, which can be assembled as well as removed easily, without drilling into the mortuary bed surfaces, is the most appropriate solution for our workplace. Since the Mae Fah Luang University Medical Center Hospital was only established at the end of 2018, currently there is only a single forensic doctor and as yet no mortuary staff. The hospital is therefore unable to perform a legally necessary autopsy at this time. Therefore, the testing of machinery function and controlling interfaces is possible in this situation. Certainly, we will operate a dissection as well as a test in humans as soon as possible.

Secondly, the design and layout of a mortuary should provide crucial support services for healthcare workers in suspected COVID-19 cases. For example in the UK, adequate ventilation is mandated, any electric saw should have a vacuum dust collector, and also all essential devices should be equipped for the dissection, in a manner to restrict walking in and out the mortuary place (Hanley et al. 2020). In the USA, deceased persons with known or suspected COVID-19 will have an autopsy procedure performed if they are declared as cases involving medicolegal jurisdiction, or family and cultural wishes. If an autopsy is performed, pulmonary and upper airway tissues should be collected and fixed with formaldehyde (Center for Disease Control and Prevention 2020). A research article in Germany revealed that the autopsy findings in COVID-19 cases showed specific pathologic findings in many organs, such as coronary heart disease, chronic obstructive pulmonary disease, deep venous thrombosis, pulmonary embolism, and diffuse alveolar damage (Wichmann et al. 2020). As in Italy, the extraction of the oral, cervical, and thoracic structures, also called "en bloc" extraction, is performed for the investigation of COVID-19 cases, which require the taking of lung swabs during the autopsy operation (Santurro et al. 2020). Clearly open dissection in cases of COVID-19 is still necessary. An electric saw should be installed near the autopsy bed for supporting mortuary staff that is easy to use and that incorporates an anti-dust spreading device.

Thirdly, consideration must be given to the fact that the survival rate of some human coronaviruses, including Severe Acute Respiratory Syndrome (SARS) and Middle East Respiratory Syndrome (MERS) on inanimate surfaces, such as plastic, glass, and metal, shows persistence of up to 9 days (Kampf et al. 2020). A human corpse is declared as a lifeless body, but at present, it is unclear how long viruses can remain infective. Therefore, a new autopsy machine should be able to be operated via a wireless remote control, to prevent the mortuary workers being exposed to unnecessary risk from the corpses.

Finally, having noted some limitations of the previous robotic autopsy saw, the new funeral saw technology should be able to cut bones or soft human tissues in any plane and direction. 
Fig. 1 Design of cadaveric skull and tissue cutting manipulator

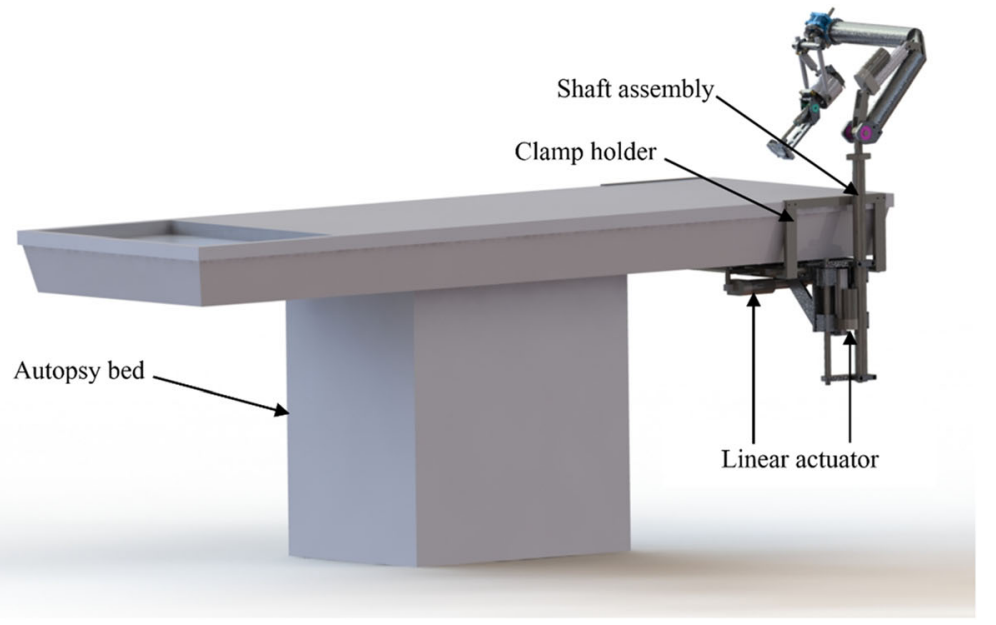

\section{Machinery and control system design}

As part of machinery design, Solidworks 2017 software was chosen for the creation of this machine. The cadaveric skull and tissue cutting manipulator consists of a clamp holder, designed specifically for autopsy bed attachment. The saw frame position can be adjusted vertically as well as horizontally to the bed according to the size of the cadaver. For easy maintenance, the manipulator can be separated from the clamp holder and shaft assembly. This machine allows the adjustment of the angle for bone and tissue cutting and the height of saw blade can also be altered related to the size of target object. The saw frame can be turned around in the calvarium for skull cutting. The saw blade is coupled with the saw blade depth controller to minimize secretion spreading. The mechanical drawings are shown in Fig. 1 and Fig. 2. The dimensions of this manipulator are outlined in Fig. 3. Almost the structure and components of the cadaveric skull and tissue cutting manipulator were made of aluminum alloy and 304 stainless steels, to guarantee that the instrument can prevent corrosion from rust, humidity, and chemical agents.

For electrical safety mains, $220 \mathrm{~V}$ AC passes through an AC earth leakage circuit breaker (ELCB) set to $30-\mathrm{mA}$ sensitivity. It is converted to $24 \mathrm{~V} \mathrm{AC}$ by a transformer and
Fig. 2 Design of saw blade set of manipulator

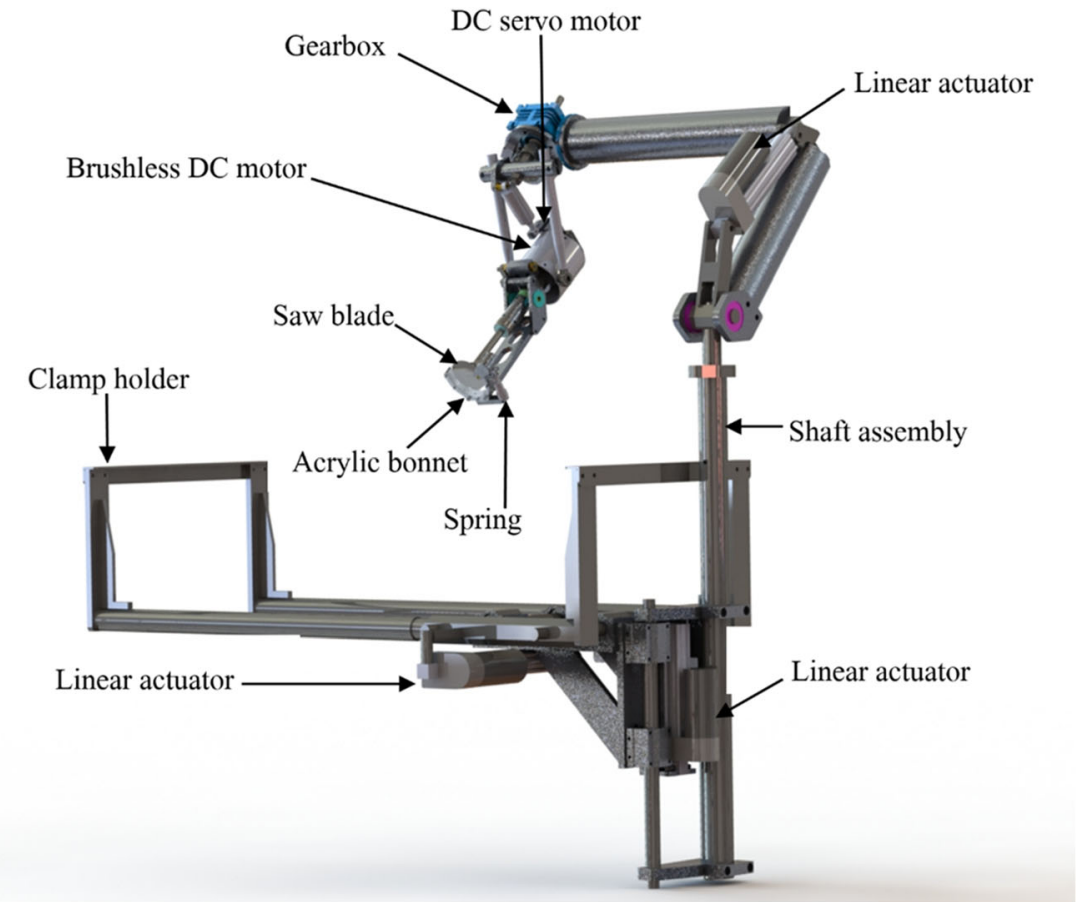


Fig. 3 Dimensions of the manipulator (millimeter)
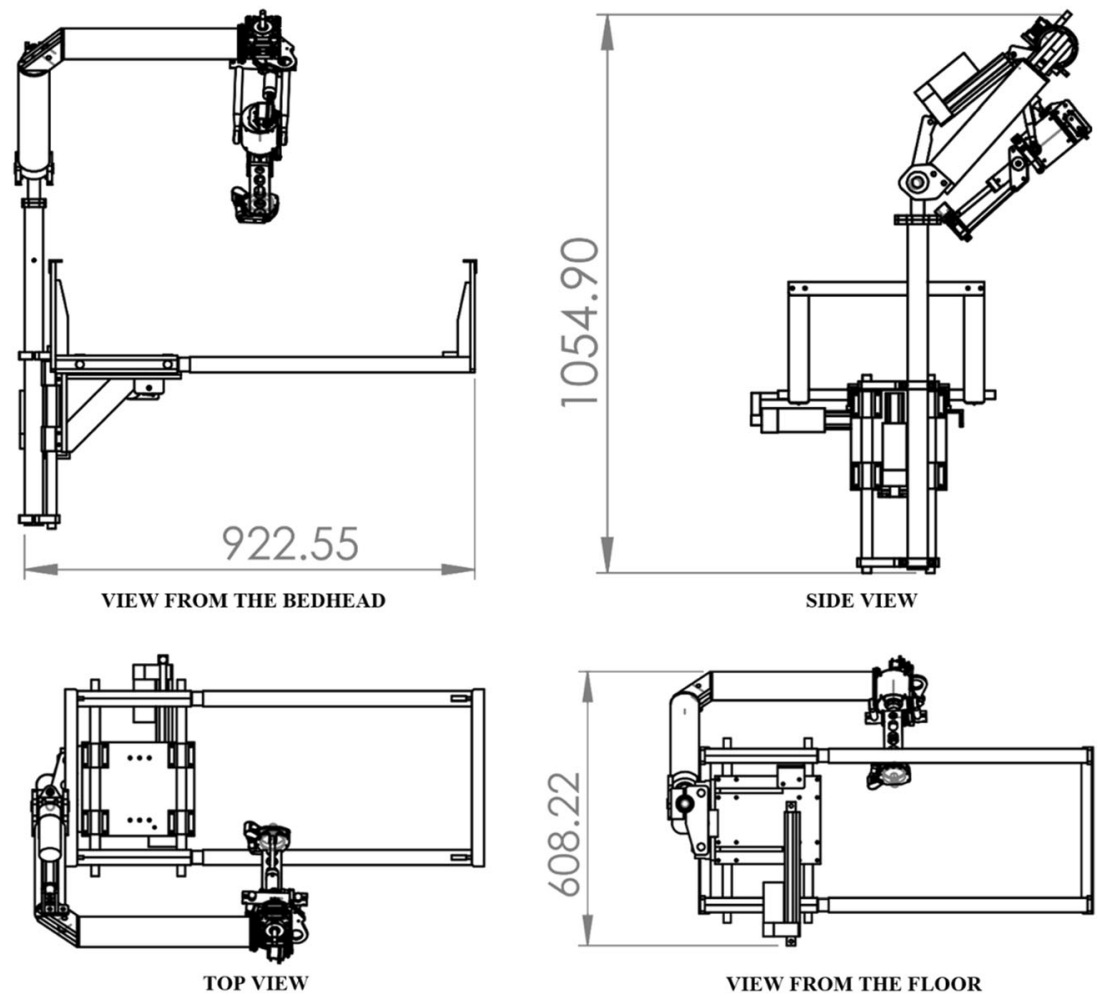

modified from alternating current to direct current by an AC$\mathrm{DC}$ converter circuit with DC breaker rated at $40 \mathrm{~A}$. These are housed in a nano-electric enclosure water-proof box, measuring $324 \times 414 \times 170 \mathrm{~mm}$, for protection from humidity and moisture. A pulse width modulation (PWM) system, which can adjust the motor speed from 0 to $100 \%$, is used for the motor control system.

To optimize distancing of the mortuary staff away from the corpses, an unmanned aerial vehicle (UAV) remote control, model $10 \mathrm{CH} 2.4 \mathrm{GHz} 6 \mathrm{~V}$ DC $1.5 \mathrm{AA} * 4$ AFHDS $2 \mathrm{~A}$ signal operation, with a transflective STN positive screen, with white backlight, was used to provide wireless technology.

\section{Results}

The prototype of cadaveric skull and tissue cutting manipulator (see Fig. 4) was constructed and underwent primary testing. The results are described as follows.

\section{Machinery functions}

Firstly, three DC 100-mm stroke linear actuator motors, with motor drivers, are used for the positioning of the manipulator. Dual linear actuator motors, coupled with a clamp holder, are used to control the saw frame position, with an approximately
Fig. 4 Prototype of cadaveric skull and tissue cutting manipulator

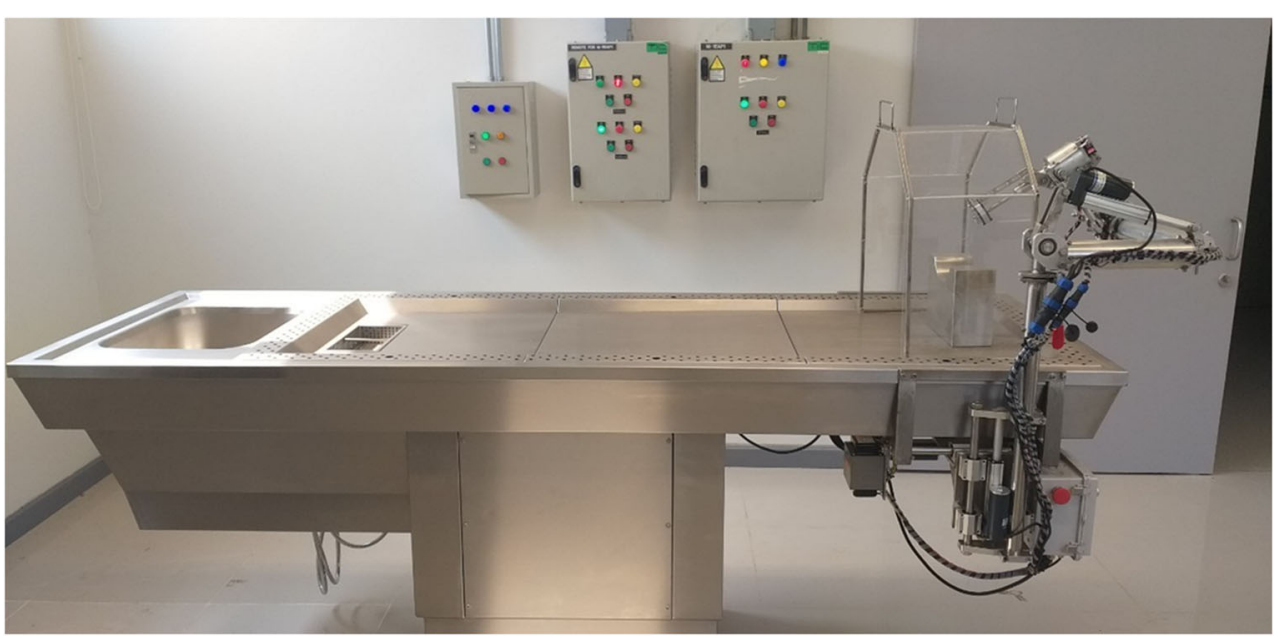




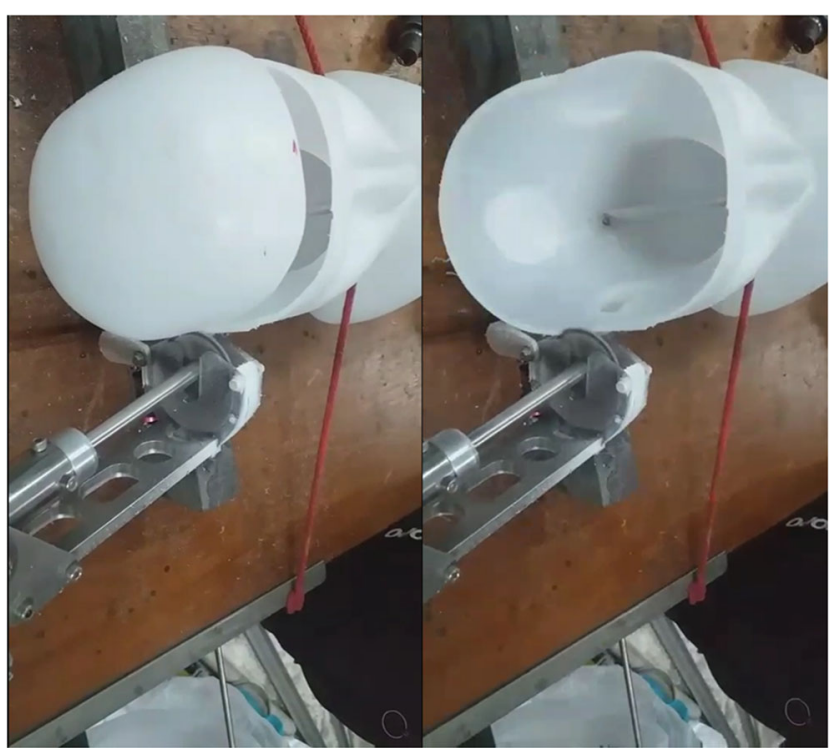

Fig. 5 The cutting of the plastic head model using the cadaveric skull and tissue cutting manipulator

10-cm range in horizontal and vertical directions. A further motor is used for skull cutting angle adjustment, attached to the center joint of the manipulator, allowing elevation up to $30 \mathrm{~cm}$ in height.

Secondly, the saw frame can be turned through $360^{\circ}$ for skull and tissue cutting, at a rotational speed of 1 RPM, using a modified gearbox powered by a DC gear motor $24 \mathrm{~V} @ 20$ RPM.

Thirdly, a digital DC titanium gear servo coreless motor is used for the control of saw blade depth, allowing adjustment from 0 to $3 \mathrm{~cm}$ to minimize tissue damage.

Fourthly, the rotational speed of the saw blade is controlled, from 0 to 10,080 RPM, by a 420-KV out-runner brushless DC electric motor, integrated with a brushless speed controller, created using driving efficiency optimization (DEO) technology.

Finally, to prevent environmental contamination, including bacteria, fungi, and viruses, the saw blade is sheathed by an acrylic bonnet, which combined with a spring which is held alongside the saw blade close to the object being cut. The test of the cutting of the plastic head model using this manipulator is shown in Fig. 5.

\section{Controlling ability}

The remote control can operate all the functions of the machinery. The users can perform skull and tissue cutting procedures remotely at a distance of at least $20 \mathrm{~m}$ away from the manipulator within an autopsy suite.

\section{Discussion}

The new compact autopsy manipulator can be attached to an autopsy bed without drilling. It is likely that COVID-19 cases can possibly transmit the virus from either the lungs or infected organs to the mortuary worker. Therefore, to restrict pathogenic spreading, the mortuary staff should make use of some additional respiratory protection during procedures, such as bones and skulls cutting, by physical distancing via the wireless remote control (World Health Organization 2020). The acrylic bonnet, which covers the saw blade, and the mobile acrylic head box can reduce this risk.

Following the trend of development of smart surgical robotic systems, the medical innovators have focused on some advanced techniques. An example is enhanced imaging to overcome the limitations of human eyes, images via cameras, intelligent systems for real-time feedback, surgeon control consoles, haptic feedback, artificial intelligence, automated surgery, etc. (Chang et al. 2018). High-resolution of postmortem MRI, also called virtual autopsy or virtopsy, has become an essential technique for histopathological investigation, particularly neuroimaging analysis. Postmortem MRI, which should be considered clinical correlations, usually incorporates digital cameras or scanners, artificial intelligence, and machine learning (O'Sullivan et al. 2019). Another virtopsy technique, which reveals the powerful imaging of bone fractures and soft tissue injuries, is postmortem multislice computed tomography (PMCT). The application of PMCT in the field of forensic pathology is used for the analysis of the cause of death, for example, traffic accidents, fall from height, drowning, head injuries, gunshot injuries, cerebrovascular diseases, coronary artery diseases, pulmonary embolization, neonatal malformations, and medical malpractice; even though PMCT has many advantages, it needs special machine controller training and the machine is too expensive (Wan et al. 2020). In general, global autopsy rates have been dropped continuously and they have been replaced by imaging-based autopsies. By the way, according to the postmortem COVID-19 pulmonary findings, the process of lung tissue biopsy fixed in $10 \%$ buffer formalin, then, stained by hematoxylin and eosin, as well as immunohistochemical agents, also has been essential yet (Carsana et al. 2020). Therefore, dissection and biopsy are still necessary in this COVID-19 situation. The cadaveric manipulator will possibly amalgamate with imaging techniques, informatics, and also robotic technologies in the future. However, due to the financial effects of COVID-19, on budgets supporting research and development of medical devices, the intelligent multifunction autopsy machine will be fabricated and developed when the global crisis is resolved and financial stability returns. Further development of this machine will be required in that at present that it cannot be moved for procedures on bones and connective tissues located beyond the autopsy bedhead.

In summary, this machine overcame some limitations of prior skull and tissue cutting prototypes in that it was able to cut spherical objects, similar to a calvarium, to cut a piece of wood, and also soft tissues. However, it can only work if it is 
attached to the bedhead and its function is limited to tissue, bone, and skull cutting techniques, separating it from global trends in multipurpose machinery design. As part of control system design, however, this control system could not function as smoothly as a hand control or with the sensitivity of more refined internet of things technology.

\section{Conclusions}

Responding to the risk of airborne infection and the COVID19 crisis, this manipulator demonstrated the development of autopsy equipment, making use of robotic and wireless technology. Further development should consider how to construct either a full autopsy robot or a multipurpose autopsy device, which can cut different organs and bones, slice tissues, take photographs, and also infuse some preservative agents into corpses, without the necessity of autopsy staff being in close proximity to the autopsy bed. The wireless control system needs to be enhanced to take advantage of Internet of things technology. In the future, when the hospital is ready to commence officially mandated autopsy procedures, further experimentation and research can be carried out. Certainly, on behalf of medical personnel, the author hopes this prototype may inspire colleagues to improve the safety environment within autopsy units to minimize the risks of the spreading of airborne diseases and COVID-19.

Acknowledgments The author would like to thank Dr. Roger Timothy Callaghan, MB, ChB, School of Medicine, Mae Fah Luang University for grammatical support and Mr. Watchara Jamnuch, an electrical engineer, for technical support.

Authors' contributions Not applicable.

Funding The funding was provided by Mae Fah Luang University, included within an annual government statement of expenditure for purchasing autopsy equipment, fiscal year 2019.

Data availability Not applicable.

\section{Compliance with ethical standards}

Conflict of interest The author declares that he has no conflict of interest.

Code availability Not applicable.

\section{References}

Blokker BM, Weustink AC, Wagensveld IM, von der Thüsen JH, Pezzato A, Dammers R, et al. Conventional autopsy versus minimally invasive autopsy with postmortem MRI, CT, and CTguided biopsy: comparison of diagnostic performance. Radiology. 2018;289:658-67.

Carsana L, Sonzogni A, Nasr A, Rossi RS, Pellegrinelli A, Zerbi P, et al. Pulmonary post-mortem findings in a series of COVID-19 cases from northern Italy: a two-centre descriptive study. Lancet Infect Dis. 2020;20:1135-40. https://doi.org/10.1016/S1473-3099(20) 30434-5.

Center for Disease Control and Prevention. Collection and submission of postmortem specimens from deceased persons with known or suspected COVID-19 interim guidance. 2020. https://www.cdc. gov/coronavirus/2019-ncov/hcp/guidance-postmortem-specimens. html. Accessed 23 Jun 2020.

Chang K, Raheem A, Rha K. Novel robotic systems and future directions. Indian J Urol. 2018;34:110-4.

Hanley B, Lucas SB, Youd E, Swift B, Osborn M. Autopsy in suspected COVID-19 cases. J Clin Pathol. 2020;73:239-42.

International Labour Organization. THE CRIMINAL PROCEDURE CODE. 2008. http://www.ilo.org/dyn/natlex/docs/MONOGRAPH/ 93536/109383/F203580879/THA93536\%20EngTha.pdf. Accessed 17 Jun 2020.

Jumlongkul A, Chutivongse P. Design and fabrication of robotic autopsy saw. In: Proceedings of the 2019 9th International Conference on Biomedical Engineering and Technology - ICBET' 19. ACM Press. 2019; https://doi.org/10.1145/3326172.3326177.

Kampf G, Todt D, Pfaender S, Steinmann E. Persistence of coronaviruses on inanimate surfaces and their inactivation with biocidal agents. $\mathrm{J}$ Hosp Infect. 2020;104:246-51.

Nunes Duarte-Neto A, de Almeida Monteiro RA, da Silva LFF, Malheiros DMAC, de Oliveira EP, Theodoro Filho J, et al. Pulmonary and systemic involvement of COVID-19 assessed by ultrasound-guided minimally invasive autopsy. Histopathology. 2020;77:186-97. https://doi.org/10.1111/his.14160.

O’Sullivan S, Heinsen H, Grinberg LT, Chimelli L, Amaro E, do Nascimento Saldiva $\mathrm{PH}$, et al. The role of artificial intelligence and machine learning in harmonization of high-resolution postmortem MRI (virtopsy) with respect to brain microstructure. Brain Inform. 2019. https://doi.org/10.1186/s40708-019-0096-3.

Santurro A, Scopetti M, D'Errico S, Fineschi V. A technical report from the Italian SARS-CoV-2 outbreak. Postmortem sampling and autopsy investigation in cases of suspected or probable COVID-19. Forensic Sci Med Pathol. 2020. https://doi.org/10.1007/s12024020-00258-9.

Wan L, Song YX, Li ZD, Liu NG, Wang YH, Wang MW, et al. The approach of virtual autopsy (VIRTOPSY) by postmortem multislice computed tomography (PMCT) in China for forensic pathology. Forensic Imaging. 2020;20:200361. https://doi.org/10.1016/j.fri. 2020.200361.

Wichmann D, Sperhake J-P, Lütgehetmann M, Steurer S, Edler C, Heinemann A, et al. Autopsy findings and venous thromboembolism in patients with COVID-19: a prospective cohort study. Ann Intern Med. 2020;173:268-77. https://doi.org/10.7326/M20-2003.

World Health Organization. Infection Prevention and Control for dead body management in the context of COVID-19: Interim guidance. 2020. https://apps.who.int/iris/bitstream/handle/10665/331538/ WHO-COVID-19-1PC_DBMgmt-2020.1-eng.pdf. Accessed 20 Apr 2020.

Publisher's note Springer Nature remains neutral with regard to jurisdictional claims in published maps and institutional affiliations. 